\title{
A Psicologia e as problemáticas relacionadas à violência e aos direi- tos humanos: o papel e o posicionamento do psicólogo
}

Psychology and the problems related to violence and human rights: the role and positioning of psychologists

http://dx.doi.org/10.5007/2178-4582.2014v48n2p234

Mérly Luane Vargas do Nascimento

Universidade Estadual de Maringá, Maringá, PR/ Brasil

\begin{abstract}
As questões relativas à violência e aos direitos humanos, embora não recentes, são determinadas por condicionantes complexos que dão origem a discussões recorrentes no campo das ciências humanas. Tais questões desafiam profissionais de várias áreas do conhecimento na busca de instrumentos e estratégias para lidar com as diferentes demandas sociais delineadas nesse cenário. $\mathrm{O}$ objetivo deste trabalho é discutir alguns conceitos e problemáticas que dele se desdobram, especificamente no que se refere à constituição do campo científico e profissional da Psicologia. Para tanto, são feitas algumas considerações acerca das definições conceituais e sociais concernentes à violência e aos direitos humanos, visando situar melhor a demanda endereçada ao profissional da psicologia, fazer uma reflexão crítica sobre essa demanda e tecer considerações sobre tal atendimento.
\end{abstract}

Palavras-chave: Violência - Direitos Humanos - Psicologia
The issues relating to violence and human rights, although not new, are determined by complex determining factors which give rise to recurrent debates in the field of human sciences. Such issues challenge professionals from different areas of knowledge in the search for tools and strategies to deal with the different social demands outlined in this scenario. The objective of this paper is to discuss some concepts and issues that are developed, specifically with regard to the constitution of scientific and professional field of psychology. Therefore, we make some comments on the social and conceptual definitions on violence and human rights in order to better situate the demand addressed to professional psychology, reflect critically on this demand and discuss such care.

Keywords: Violence - Human Rights - Psycho$\log y$.

\section{Introdução}

A Psicologia, enquanto ciência e profissão, parece suscitar a constituição de representações sociais bastante ambíguas e até mesmo ambivalentes, as quais costumam expressar diferentes graus e qualidades de valorização, expectativas, atribuição de relevância, entre outras.

Se, por um lado, há em nossa sociedade brasileira contemporânea certos preconceitos velados ou explícitos acerca do que significa consultar um psicólogo, precisar de uma orientação ou tratamento psicológico, ou simplesmente ser um psicólogo, por outro, ao redor das noções socialmente elaboradas e 
difundidas sobre a Psicologia, gravitam expectativas e demandas por serviços e saberes que estariam além daqueles exequíveis por qualquer ser humano, que atribuem ao psicólogo habilidades análogas àquelas supostas a um mago, guru, profeta, divindade, e assim por diante.

É desse modo que os psicólogos, por vezes, partilham uma condição peculiar e paradoxal que, ao mesmo tempo que os estigmatiza - como vagabundos ou loucos, por exemplo, - também os convida a responderem perguntas e a resolverem problemas de forma mágica e linear, não obstante a perceptível complexidade dos objetos a serem analisados em tais situações.

Quando o que está em questão é o que o senso comum entende por episódios de violência, essa demanda endereçada ao psicólogo pode conter algumas armadilhas, tanto para o profissional quanto para essa ciência (CANIATO, 2008). O mesmo ocorre em relação a temáticas relativas aos chamados direitos humanos. Por esse motivo, seria prudente analisar, desde o momento em que se recebe um pedido por soluções em forma de sortilégios em relação a tais objetos de estudo, quais intenções e metas, objetivas e subjetivas, lhe fornecem substrato.

Parece pertinente considerar que, ao falarmos de violência e direitos humanos, há uma dificuldade adicional: a criação sistemática de obstáculos à visão e compreensão das pessoas em geral acerca dos fatores intervenientes na violência, sobretudo daqueles relacionados à manutenção de privilégios e poderes de uma ínfima minoria em detrimento dos demais.

É possível que justamente em virtude desses obstáculos à percepção da maioria das pessoas quanto aos fatores que geram e perpetuam a violência em nossa sociedade é que haja tão grande destaque, e até mesmo sensacionalismo, em torno de episódios de violência subjetiva e, concomitantemente, um silêncio ensurdecedor acerca da violência objetiva que lhe serve de sustentáculo (ZIZEK, 2014). É assim que, por exemplo, há grande estardalhaço midiático em torno de manifestações que terminam em pancadaria, bombas de gás lacrimogêneo e violência policial, porém pouca investigação e espaço - nos mesmos telejornais ou revistas impressas - de discussão sobre as situações sub-humanas de trabalho, os privilégios de classe e as formas autoritárias de repressão estatal que concorrem para a ocorrência de tais infelizes episódios.

Caso o psicólogo apenas aquiesça em analisar os fenômenos da violência subjetiva em detrimento de seus determinantes objetivos, historicamente constituídos, poderá até atender algumas demandas sociais que lhe são endereçadas; não obstante, deve estar ciente da mutilação de sua própria ciência promovida por atitudes como essas, que evitam desfazer o véu ideológico que cerca a divulgação de notícias e informações sobre a violência, ao mesmo 
tempo em que renunciam à possibilidade de transcender a realidade dada e as formas estabelecidas de viver, o que significaria, em última instância, renunciar a um pensamento racional, ou seja, ao "modo de pensar e de agir que está orientado para reduzir a ignorância, a destruição, a brutalidade e a opressão" (MARCUSE, 1982, p.140). Isso pode significar a sutil diferença entre combater ou corroborar aqueles mesmos fenômenos violentos que são objetos de estudo ou análise do psicólogo em questão.

É por isso que o estudo e as considerações psicológicas acerca dos fenômenos violentos na contemporaneidade devem ser iniciados com a definição do conceito de violência e a diferenciação entre os modos de violência subjetiva, objetiva e simbólica. Tais modos de violência, normalmente, combinam-se em uma interação complexa na ocorrência de fenômenos violentos, embora sua expressão mais ruidosa e visível tenda a evidenciar os aspectos subjetivos da violência .

\section{A violência enquanto objeto de estudo e intervenção do psicólogo}

Com o intuito de promover considerações mais cuidadosas em relação à violência, vamos nos deter um pouco mais na tarefa de explicitar tal conceito. Substantivo abstrato, a violência, por definição, depende de outros seres para existir. Isso significa, entre outras coisas, que a violência não surge ou se perpetua sem que seja perpetrada por algo ou alguém. E aqui, não teremos apenas substantivos concretos que determinam a existência da violência, mas também a paradoxal ideia de abstrações que se concretizam, embora nem sempre possam ser nitidamente percebidas. Alguns exemplos de abstrações concretizadas são as práticas sociais e intersubjetivas calcadas em preconceitos e discriminações diversas, as quais tornam-se manifestamente violentas de diferentes formas.

Além disso, não se trata de confundir concretude com aquilo que podemos pegar, apalpar, cheirar e aplicar todo nosso empirismo científico, ainda hoje tão exaltado na academia. Trata-se de uma concretude mais abrangente e definitiva. Podemos apontar, por exemplo, como forma de violência objetiva e concreta, as catastróficas consequências do funcionamento regular de nossos sistemas econômico e político. Embora possa não ser visível ou palpável em muitas de suas manifestações, a concretude da violência de nosso modo de organização social revela-se nas centenas de milhares de pessoas privadas de seus direitos básicos e em um sistema engendrado para o benefício de poucos: 
e faculdades humanas; sua paz, mantida pela constante ameaça de guerra, seu crescimento, dependente da repressão das possibilidades reais de amenizar a luta pela existência - individual, nacional e internacional (MARCUSE, 1982, p.14)

Desse modo, podemos considerar como determinantes, e mesmo sujeitos da violência, não só os seres humanos, as instituições e os entes visíveis; mas também aquilo que, embora objetivo, é invisível: o sistema, o que está instituído ao nosso redor - às vezes, até, dentro de nós, embora negado ou cuidadosamente extirpado da memória - , a produção simbólica e seus núcleos privilegiados de veiculação, entre outros que podemos considerar determinantes objetivos da violência em suas diferentes nuances.

$\mathrm{Na}$ tentativa de melhor compreender a constituição da violência, proponho analisar a proposição de Zizek (2014) segundo a qual a violência possui uma natureza que é, por vezes, de difícil apreensão e de caráter paralaxe. Tal proposição implica o reconhecimento de que, ao tratar a questão da violência, teremos que situá-la em relação a um sujeito, um objeto, um meio ou instrumento e, assim por diante. A paralaxe é um termo bastante utilizado para nomear um fenômeno conhecido em astronomia: refere-se a um aparente deslocamento de um objeto observado que, de fato, é causado por uma mudança no posicionamento do observador. Se alguém olhar, por exemplo, uma paisagem posicionando o dedo verticalmente em seu centro e fechar um dos olhos, a verá em determinada posição. Mas, ao inverter essa condição, abrindo o olho inicialmente fechado e fechando o outro, a posição do objeto será aparentemente alterada. Esse deslocamento aparente do objeto é o que a paralaxe exprime. O objeto, a paisagem, não mudou ou se mexeu. O que houve, de fato, foi um deslocamento ou, ainda, uma mudança de perspectiva do observador.

Admitir hipoteticamente, portanto, que a violência tem uma natureza paralaxe é reconhecer que o posicionamento de quem a estuda, analisa ou discute está intimamente relacionado ao que verá ou conseguirá abstrair e entender sobre ela. Isso porque a análise da constituição de suas "cores" e "nuances", ou seja, a investigação das causas, implicações e desdobramentos em suas diferentes formas de manifestação será sobremaneira influenciada por esse lugar ocupado - e, algumas vezes, assumido - pelo observador.

Em relação a tal posicionamento do psicólogo que investiga a violência, embora possamos utilizar diversos parâmetros de localização (metaforicamente ou concretamente falando), parece particularmente interessante, para os propósitos do presente trabalho, destacar dois deles. Em primeiro lugar, para finalidades acadêmicas teríamos que pensar em um posicionamento epistemológico, ou seja, a partir de qual viés teórico e metodológico o objeto 
"violência" será investigado. Por outro lado, para finalidades, por assim dizer, críticas e históricas, objetivando analisar as implicações para o sujeito e o objeto da violência, teríamos que pensar em um posicionamento político, ou seja, um posicionamento em relação à coletividade e como essa é constituída contemporaneamente. O termo grego "polis", do qual a palavra política se origina designa a "cidade-estado", na qual os cidadãos, pretensamente livres e iguais, exerceriam sua cidadania, ou seja, seus direitos e deveres em relação à coletividade representada pela cidade-estado. Não é nosso objetivo aqui definir ou explorar pormenorizadamente o significado de cidade-estado ou de política. Tampouco seria o caso de adentrar os estreitos e famigerados corredores da discussão acerca das distorções ideológicas que, desde a Grécia Antiga, assombram nossas noções de democracia, igualdade de direitos e cidadania. A prática social constituída e constituinte de tais noções é aqui, antes, objeto de investigação. Basta, portanto, para os propósitos ora apresentados, reconhecer que não vivemos em uma sociedade homogênea e, além disso, que os diferentes indivíduos situam-se em relação a essa sociedade de diferentes maneiras, com diferentes poderes de influência política e econômica, e que sofrerão ou perpetrarão a violência em consonância com as implicações do status social ao qual pertencem. Isso não significa que a classe social do indivíduo determina se ele será mais ou menos violento. No entanto, implica reconhecer que as repercussões sociais da violência serão diferenciadas para cada classe. Não apenas nos fenômenos violentos, mas também em outras situações que incluem diferentes modos de relações intersubjetivas, essa influência far-se-á presente:

\footnotetext{
A posição social do indivíduo e sua relação com os demais não apenas parecem determinadas por qualidades e leis objetivas, mas também essas leis e qualidades parecem perder seu caráter misterioso e incontrolável; aparecem como manifestações calculáveis da racionalidade (científica). O mundo tende a tornar-se o material da administração total, que absorve até os administradores. (MARCUSE, 1982, p.162)
}

O posicionamento político do cientista implica não apenas diferenciar esses diferentes lugares ocupados pelos sujeitos e objetos da violência, mas também situar a si mesmo quanto às finalidades que elege ao produzir conhecimento. E aqui cabem as seguintes perguntas: Para quem produzir conhecimento? Em benefício de quais sujeitos? O objetivo final seria a alteração ou a manutenção do status quo que possibilita e, muitas vezes, reproduz e perpetua a violência analisada?

Como salienta Coimbra (2001), a Psicologia caminha orientada por modelos que, muitas vezes dizem 'o que fazer' e 'como fazer', porém omitem, 
quase sempre, o 'para quê fazer'. A compreensão das práticas psi como implicadas no mundo e implicadas com o mundo diz respeito a um necessário contraponto à posição neutro-positivista que isola e aliena o psicólogo pesquisador. Isso está intimamente relacionado não apenas ao lugar ocupado pelo psicólogo em suas práticas cotidianas, mas também ao lugar que ocupa na própria história humana. A autora lembra-nos que, pelos próprios efeitos que nossas práticas produzem no mundo, elas são sempre essencialmente de caráter político.

\section{A questão dos direitos humanos}

Ao indagarmos acerca da vulnerabilidade social (sua definição, seus contextos, sobre os indivíduos em tal situação, entre outras questões), torna-se inevitável abordar também a questão dos direitos humanos e o papel do Estado como instituição responsável por assegurar o acesso dos sujeitos a condições básicas de sobrevivência e dignidade. Nesse sentido, é a ação ou omissão do Estado que o tornará (ou não) agente perpetrador de violência contra os direitos humanos.

No caso de um Estado neoliberal - caracterizado, mormente, pela mínima proteção social e o máximo respeito às leis impessoais do mercado -, a negligência em relação aos direitos humanos figura como um pressuposto de sua política. As implicações sociais disso são bastante conhecidas: em uma constante luta pela autoconservação regida por uma lógica concorrencial e individualista, serão justamente os indivíduos ou classes mais vulneráveis - ou o comportamento daqueles que supostamente pouco ou nada têm a perder - que se tornarão mais temidos. Os instrumentos repressivos estatais, justificados por um modo de pensar paranoico, estrategicamente cultivado e veiculado pela mídia subserviente ao poder, terão, assim, liberdade para impor a tais indivíduos sua dose extraordinária de violência. A criminalização da pobreza, juntamente com a tortura física, moral e psicológica destinada diariamente a grandes parcelas da população (ALMEIDA, 2009), podem ser consideradas, portanto, apanágio frequente, embora, simultaneamente, refugo inconfesso e controverso do modo de funcionamento do Estado neoliberal capitalista.

Além disso, o movimento imprevisível dos recursos - guiados unicamente por imperativos de rentabilidade econômica - gerarão um clima de insegurança no qual os indivíduos estão lançados à própria sorte nos meandros impessoais do mercado. A violência proveniente dessa desatenção aos direitos básicos historicamente constituídos - tais como a saúde e a previdência social, destinados a amparar o indivíduo em caso de doença e desemprego e amparar sua família em caso de morte - tende a originar outras tantas violências ou 
sofrimentos: competição frenética e com requintes de crueldade, proletarização dos trabalhos e desvalorização dos salários, sentimento de inquietude e ansiedade frequentes, entre outros.

Não é mero acaso que, conforme nos permite compreender alguns dos mais proeminentes sociólogos e estudiosos contemporâneos(BAUDRILLARD, 1995; BAUMAN, 2008; LIPOVESTKY, 2007), o medo vem a ser um constituinte fundamental da subjetividade contemporânea.

A mentalidade sobreviventista, tal como nomeada por Lasch (1983), não pode ser ignorada pelo psicólogo já que, de diversas maneiras, ela chegará aos consultórios em que atendemos, às nossas escolas, universidades, hospitais, postos de saúde, e, enfim, aos nossos mais diversos locais de trabalho, emoldurando diferentes demandas ou queixas psicológicas. À medida que ameaça o vínculo de confiança e de solidariedade com o outro, ela tende a ser um elemento destrutivo, tanto para a subjetividade quanto para a sociedade que a abriga, trazendo sofrimento psíquico e acirrando o sentimento de desamparo já inerente à nossa condição humana. Conforme assinalou Adorno (2008, p.189), "várias situações históricas e sociais favorecem diversas síndromes psicológicas e "trazem à tona" ou acentuam tipos distintos de possibilidades sempre presentes nos seres humanos".

Zizek (2014, p.25), nos fala sobre a "dança especulativa 'solipsista' do capital, que persegue seu objetivo de rentabilidade numa beatífica indiferença ao modo como tais movimentos afetarão a realidade social”. É forçoso notar que esta não é apenas uma ameaça para a sobrevivência humana em um futuro distante (ou futuro próximo, como alguns ecologistas preveem). Se a sobrevivência nesse sistema é um imperativo tão poderoso é porque ela tem sido dificultada de diversas formas. Para muitos, essa dança solipsista é, inclusive, mortífera agora mesmo. Que o digam as centenas de milhares de pessoas mortas pela fome ou, ainda, aquelas que tiveram seu países assolados por guerras em decorrência de disputas por terra, petróleo e outros recursos econômicos.

Está claro que, embora tenha em consideração todos esses aspectos da violência objetiva, ou antes, da violência que se objetiva e faz-se presente por meio de nosso próprio modo de organização social, o psicólogo poderá furtarse a uma análise mais detida e demorada que esmiúce os diversos fatores intervenientes na violência quando for convidado a explicar em palestras, cursos, disciplinas, aulas magnas ou mesmo em redes de televisão porque o fulano deformou o rosto do ciclano com objeto cortante, após uma mera briga de bar; ou, então, porque um sujeito entra em uma sala de aula por ele frequentada há certo tempo e atira abertamente em colegas de turma e professores, sem que exista um motivo aparente imediatamente identificável. 
O misto de fascínio e repulsa que a violência subjetiva costuma suscitar atinge também os cientistas e estudiosos em geral. O psicólogo, como ser humano, convidado de maneira tácita ou explícita a solidarizar-se com as vítimas atordoadas pela falta de sentido de uma explosão violenta repentina, não é uma exceção do gênero humano. A análise dos aspectos objetivos e subjacentes à violência (nem sempre facilmente apreensíveis) não é exatamente fácil de ser feita ou, antes, a expressão de uma análise mais crítica não se faz de modo exatamente descomplicado.

No entanto, vale a pena destacar a importância do fornecimento de uma visão diferente daquela calcada no âmbito exclusivamente individual, a qual costuma resultar em explicações de caráter psicológico que, exageradamente, ressaltam o aspecto orgânico (fisiológico) do comportamento, gerando caracterizações e explicações voltadas à psicopatologia.

Às vezes é preciso ter certa coragem para, deixando de apontar idiossincrasias e traços de personalidade, apontar erros de todo um modo de organização social, como o fez o autor do primeiro mapa da violência em 1998:

\footnotetext{
Não acreditamos que a juventude seja produtora de violência. As novas gerações, mais que fatores determinantes da situação de nossa sociedade, são um resultado da mesma, espelho onde a sociedade pode descobrir suas esperanças de futuro e também seus conflitos, suas contradições e, por que não, seus próprios erros (WAISELFISZ, 1998, p. 9)
}

O estudo objetivou, nas próprias palavras de seu organizador, realizar uma leitura social da mortalidade violenta de jovens brasileiros no final do século. Após mais de uma década de publicações, esse trabalho rendeu, além de dados essenciais para a pesquisa acerca do temáticas relacionadas à violência entre jovens, também o prêmio Nacional de Segurança Pública e Direito Humanos concedido em 2013 pela Presidência da República pelo conjunto da obra de Júlio Jacobo Waiselfisz.

\section{Afinal, o que são direitos humanos?}

Tendo sido situados alguns parâmetros para a questão do posicionamento do psicólogo como cientista e profissional em relação à violência, e também discutida a questão dos direitos humanos em nossa sociedade, entra em questão, por fim, a própria definição de direitos humanos e do que vem a ser a violência contra tais direitos. 
Conforme sabemos, a gênese das discussões sobre direitos humanos na modernidade coincidiu com a emergência do capitalismo industrial e esteve originalmente atrelada aos ideais apregoados pela Revolução Francesa - igualdade, liberdade e fraternidade -, os quais tornaram-se, a partir do século XVIII, sinônimos de direitos inalienáveis da essência do que é ser humano.

A fisionomia particular dos direitos humanos no interior do capitalismo foi delineada pelos burgueses insurgentes contra o absolutismo europeu a partir do direito primeiro da propriedade privada, do qual decorreriam os demais direitos. Os direitos concebidos como inalienáveis, e quase como partes naturais do homem, na realidade, revelamse, hoje, como direitos reservados às elites, enquanto continuam a ser negados aos segmentos pauperizados da população, aos marginais, aos deficientes; enfim, àqueles considerados desviantes ou miseráveis de toda espécie. É como se os direitos humanos de tais pessoas fossem colocados entre parênteses, a partir do momento em que são considerados como pertencentes a uma 'subcategoria' do gênero humano, ou talvez ainda pior que isso, como uma categoria sub-humana, inferior ao que é considerado essencialmente humano.

Não obstante, o fato de que a Declaração Universal dos Direitos do Homem, aprovada pela Assembleia Geral das Nações Unidas em 1948, é aberta com a afirmação de que "todos os seres humanos nascem livres e iguais, em dignidade e direitos", sabemos que esta realidade não é vivenciada no mundo real dos homens concretos. Do mesmo modo, os direitos estabelecidos na mesma Declaração, embora reconhecidos como universais são, constantemente, violados. No Brasil, temos mostras praticamente diárias dessas violações nos noticiários: vez por outra aparece uma fazenda na qual se denuncia o trabalho escravo, ou provas de tortura física moral e psicológica em presídios, caindo por terra qualquer ilusão idílica em relação aos ideais democráticos e humanitários.

De acordo com Benevides (2004, p. 44) "Nenhum outro tema desperta tanta polêmica em relação ao seu significado, ao seu reconhecimento, como o de direitos humanos". Isso porque ele envolveria, concomitantemente, questões ambíguas, questões consideradas praticamente redundantes e também questões demasiado controversas, que 
justapõem interesses divergentes e diferentes concepções de homem, de mundo, de cidadania, de direitos, dentre outras. Não é raro que se faça referência aos direitos humanos no sentido pejorativo ou excludente, no sentido de compreendê-los como 'direitos dos bandidos'. Não é mero acaso que seja justamente nos países, comunidades e lugares onde mais os chamados direitos humanos são violados, naquelas sociedades mais marcadas pela discriminação, pelo preconceito e pelas mais variadas formas de racismo e intolerância, que a ideia de direitos humanos permanece mais deturpada e associada a conotações e representações negativas (BENEVIDES, 2004). É nesse sentido que a autora aponta a necessidade de situar adequadamente a problemática referente aos direitos humanos no Brasil.

Arendt (1990) concebe que os direitos humanos não são um dado, algo pronto e acabado, mas referem-se a uma invenção humana em constante processo de construção e reconstrução. Nesse sentido, por estar particularmente implicado na construção de uma ciência com elevado nível de compromisso e de responsabilidade social (que é como, queiramos ou não, constitui-se a Psicologia), o papel de cidadão do psicólogo perpassa também a tarefa de construir e sustentar determinadas ideias e práticas a esse respeito.

Coimbra (2001) aponta a necessidade de, no campo dos direitos humanos, mudarmos o foco da universalidade do homem para a universalização do compromisso com a vida, assim como o foco centrado no indivíduo tornar-se-ia uma luta pelo processo de individuação, apoiando-se no ideal de diferenciação. Desse modo, o ser humano não seria de nenhum modo definido a partir de categorias de diferenciação, tais como gênero, etnia, classe ou orientação sexual, por exemplo. A autora defende, assim, uma perspectiva de direitos humanos calcada na possibilidade de as diferenças não serem referencial ou motivação para a desigualdade, a discriminação ou o preconceito. Do mesmo modo que a igualdade não deveria ser confundida com homogeneidade, padronização ou uniformidade. Assim, seguindo a perspectiva dos autores:

A questão da universalidade dos Direitos Humanos ganha, portanto, um outro sentido, dizendo respeito menos a uma universalidade do homem e mais à possibilidade de mobilização ou implicação dos diferentes homens na luta pela 
criação e preservação das diferentes manifestações da vida humana. Nessa outra perspectiva podemos pensar os Direitos Humanos como o direito a diferentes modos de viver e estar no mundo (COIMBRA; PASSOS; BENEVIDES, 2002, p.8)

É óbvio que a questão do posicionamento e da postura de implicação do psicólogo em relação às temáticas relacionadas à violência e aos direitos humanos trata-se apenas de um começo, perfazendo, juntamente com os conhecimentos científicos já constituídos nessa área, nada mais que um pré-requisito para situar adequadamente tais questões, tanto no interior de nossa ciência, quanto nos necessários debates interdisciplinares. Entretanto, parece ser necessário começar.

\section{Considerações finais}

A partir da constatação de que nada fazer pode custar mais caro do que tentar fazer alguma coisa em relação à temática da violência e dos direitos humanos na sociedade hodierna, somos convidados a pensar, ainda que por meio de noções abstratas, no que deve ser feito.

Por vezes, encontrar tais respostas nos demanda um alto nível de abstração em relação à realidade vivenciada, de modo que até podemos recear certo afastamento em relação ao que seriam nossos 'verdadeiros' objetos de estudo. Porém, a dicotomia, ou radical separação, entre instrumentalização teórica e atuação prática, como sabemos, diz respeito a um falseamento insustentável. Principalmente por abordarmos questões tão complexas - como geralmente são aquelas concernentes à violência e aos direitos humanos - é que é tão fundamental a sustentação teórica de nossa prática, utilizando nossa ciência como instrumento teórico e metodológico da atuação profissional; assim como o é também a transformação da teoria decorrente de ajustes e observações realizados na prática.

É por tais motivos que, em não raros momentos, a necessidade de abstrair a realidade para transcendê-la se impõe. A esse respeito, Marcuse (1962, p. 134) ajuda-nos ao elucidar que: "[...] não pensa realmente quem não faz abstração daquilo que é dado [...]. A abstração é a própria vida do pensamento, o indício de sua autenticidade". Nesse sentido, nós - os psicólogos - somos conclamados a sermos autênticos no combate à violência e às várias formas de opressão impostas aos seres humanos, assim como na luta pelas ações afirmativas na perspectiva dos direitos humanos. Afinal, também disso são feitas nossa ciência e nossa profissão. 


\section{Referências}

ADORNO, Theodor W. As estrelas descem à terra: a coluna de astrologia do Los Angeles Times: um estudo sobre superstição secundária. Trad. Pedro Rocha de Oliveira. São Paulo: Editora UNESP, 2008.

ALMEIDA, Angela Mendes. Impunidade e banalização da violência dos agentes do Estado. Projeto História - Revista do Programa de Estudos Pós-Graduados de História, São Paulo v. 38, p. 221-230, jun. 2009.

ARENDT, Hannah. As Origens do Totalitarismo. São Paulo: Companhia das Letras, 1990. $568 \mathrm{p}$.

BAUDRILLARD, Jean. A sociedade de consumo. Lisboa: Edições 70, 1995.

BAUMAN, Zygmunt. Medo líquido. Rio de Janeiro: Jorge Zahar, 2008. 237 p.

BENEVIDES, Maria Victoria. Cidadania e direitos humanos. In: CARVALHO, José Sergio. Educação, cidadania e direitos humanos. Petrópolis, RJ: Vozes, 2004. p. 43-65.

CANIATO, Angela Maria Pires et al. Violências e subjetividades. O indivíduo contemporâneo. Psicologia \& Sociedade, Florianópolis, v. 20, n. 1, p.16-32, 2008.

COIMBRA, Cecilia Maria Bouças. Psicologia, direitos humanos e neoliberalismo. Revista Psicologia Política, São Paulo, v. 1, n. 1, p. 139-148, 2001.

COIMBRA, Cecília Maria Bouças; PASSOS, Eduardo; BARROS, Regina Benevides. Direitos Humanos no Brasil e o Grupo Tortura Nunca Mais/RJ. In: RAUTER, Cristina; PASSOS, Eduardo; BARROS, Regina Benevides (Orgs.). Clínica e Política: Subjetividade e Violação dos Direitos Humanos. Rio de Janeiro: Te Corá/Instituto Franco Basaglia, 2002.

LASCH, Christopher. A cultura do narcisismo: a vida americana numa era de esperanças em declínio. Rio de Janeiro: Imago, 1983.

LIPOVETSKY, Gilles. A felicidade paradoxal: Ensaio sobre a sociedade de hiperconsumo. São Paulo: Companhia das Letras, 2007.

MARCUSE, Hebert. A ideologia da sociedade industrial. 6a Ed. Rio de Janeiro: Zahar, 1982.

UNESCO no Brasil. Declaração Universal dos Direitos Humanos. Brasília: 1998. Disponível em: <http//:unesdoc.unesco.org/images/0013/001394/139423por.pdf>. Acesso em: 13 jul. 2011.

WAISELFISZ, Julio Jacobo. Mapa da violência: os jovens do Brasil. Rio de Janeiro: UNESCO, Instituto Ayrton Senna e Garamond, 1998.

ZIZEK, Slavoj. Violência: seis reflexões laterais. Trad. Miguel Serras Pereira. São Paulo: Boitempo, 2014. 
NASCIMENTO, M. L. V. A Psicologia e as problemáticas relacionadas à violência e aos direitos...

Mérly Luane Vargas do Nascimento é psicóloga, mestre em Psicologia e professora do Departamento de Fundamentos da Educação (DFE) da Universidade Estadual de Maringá - UEM. Endereço para correspondência: Rua Patrícia, 91 Parque Residencial Patrícia. CEP 87040-450. Maringá, PR. E-mail: merly_nascimento@hotmail.com 